surveillance began in 1982. Among these infants, only one has been reported to have had acute clinical hepatitis B in early infancy.

Although the exclusion of infants of anti$\mathrm{HBe}$ positive mothers from the immunisation programme has resulted in so little ill effect, the ability to identify a subgroup of anti$\mathrm{HBe}$ positive women and to offer immunisation for their infants would make it possible to prevent the rare clinical hepatitis $B$ infection without too large an increase in numbers. However, the use of hepatitis B virus DNA hybridisation tests in place of $e$ antigen/antibody tests for antenatal patients must depend on assessments of cost and feasibility.

\section{Sheila Polakoff}

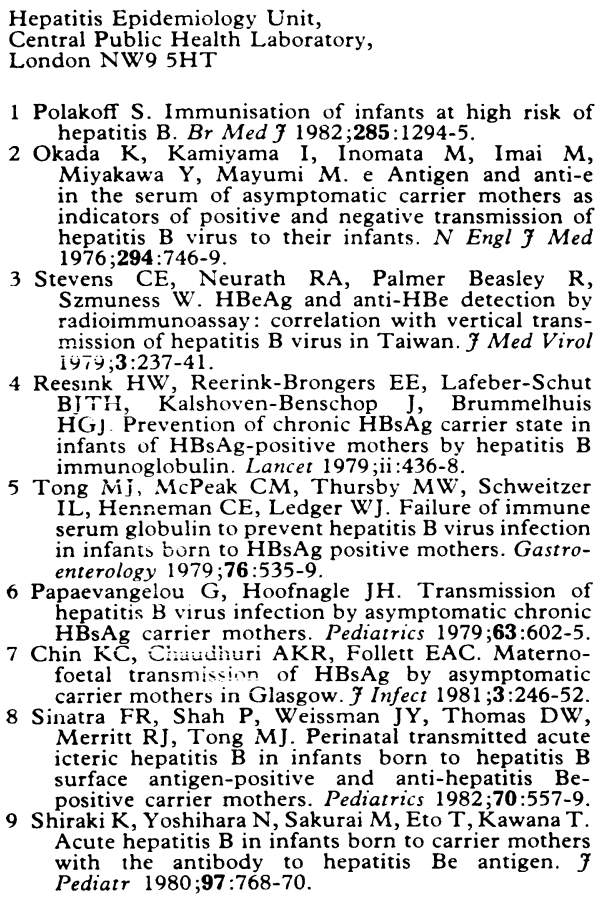

6 Papaevangelou $\mathrm{G}$, Hoofnagle $\mathrm{JH}$. Transmission of hepatitis $\mathrm{B}$ virus infection by asymptomatic chronic
HBsAg carrier mothers. Pediatrics $1979 ; 63: 602-5$. 7 Chin KC, CNiuthiuri AKR, Follett EAC. Maternofoetal transmissinn of HBsAg by asymptomatic carrier mothers in Glasgow. F Infect 1981;3:246-52.
Sinatra FR, Shah P, Weissman JY, Thomas DW, Merritt RJ, Tong MJ. Perinatal transmitted acute icteric hepatitis B in infants born to hepatitis B surface antigen-positive and anti-hepatitis Be-
positive carrier mothers. Pediatrics 1982;70:557-9.

9 Shiraki K, Yoshihara N, Sakurai M, Eto T, Kawana T. Acute hepatitis B in infants born to carrier mothers
with the antibody to hepatitis Be antigen. If with the antibody to
Pediatr 1980;97:768-70.

\section{Prevalence of hepatitis $B$ markers} among district general hospital staff

SIR,-We have read with interest Professor A J Zuckerman's review (16 February, p 492) of the prospects for new hepatitis $B$ vaccines and the letter of Drs E M Vandervelde and P P Mortimer (9 March, p 787). We fully agree with the latter authors that exposure to hepatitis $B$ virus in Britain is uncommon in hospital practice. During May and June 1983 we screened for hepatitis B markers blood specimens from 507 employees, representing $42.5^{\circ}$ of the total staff, working at Rotherham District General Hospital. The study included 29 doctors, 267 nurses, 29 medical laboratory scientific officers, 13 phlebotomists, and 169 others. All sera were tested for anti-HBs by an enzyme linked immunosorbent assay using Ausab EIA diagnostic kit (Abbott Laboratories Ltd). The sera were also examined anonymously for HBsAg by an enzyme linked immunosorbent assay using Auzyme II diagnostic kit (Abbott Laboratories Ltd).

All staff were negative for HBsAg. Serological evidence of previous hepatitis infection (positive anti-HBs) was found in 15 employees ( $\left.3^{\prime \prime}{ }^{\circ}\right)$. These were 10 doctors, four nurses, and one porter. The rate among doctors $\left(34^{\circ}\right)$ was significantly higher than that among nurses $\left(1.5^{\circ}{ }_{0}\right)(p<0.01)$. Although staff of Oriental origin (12 doctors, four nurses) represented only $3^{\circ}$. of the study population, their rate $\left(56^{\circ}{ }_{11}\right)$ was significantly higher than that for staff of Western origin $(1 \cdot 2 \%)(n=491)$, $(p<0.01)$. All the seropositive Oriental staff were doctors. The prevalence of anti-HBs in doctors of Oriental origin $\left(75^{\circ}, 9 / 2\right)$ was significantly higher than that among those of Western origin $(6 \%$ $p<0.01)$. Seropositive W'estern staff included one out of 17 doctors, four out of 263 nurses, and one porter.

The number of seropositive subjects varied between departments and was highest in the departments of orthopaedic surgery, orthodontic surgery, accident and emergency, mental subnormality, and general surgery.

The infection rate did not increase uniformly during years of employment in the specialty. No difference was noticed below 20 years of employment. The infection rates were $2 \cdot 6^{\circ}$, for up to 5 years, $3 \cdot 3{ }^{\circ}$, for $6-10$ years, $2 \cdot 3 \%$ for $11-15$ years, and zero for 16-20 years. However, the infection rate rose to $16 \cdot 6^{\circ}$ o for $21-25$ years and $6 \cdot 2{ }^{\circ}{ }_{0}$ for 26-30 years' employment.

A questionnaire was given to the 15 seropositive staff and also to 15 staff matched for age, sex, and occupation who were used as controls. The questionnaire included the country of origin; duration of stay in country of origin since birth; overseas visits and their duration; history of hepatitis or jaundice; reception of blood or blood products; previous surgery, dental surgery, bleeding disorder, tattooing, dialysis for renal failure, immunosuppression, or prophylactic or therapeutic injections; contact with cases or carriers of hepatitis; and history of any other important disease.

All of the nine seropositi e staff of Oriental origin had stayed more than 31) years from birth in India (6), Pakistan (2), or Burrna (1). Only one had a history of hepatitis. The remaining six staff were of Western origin, of whom two had had hepatitis and two were contacts of patients with hepatitis $B$. Four of the Westerners had been abroad (to Africa (1), Singapore (1), or elsewhere) for periods ranging from four months to four years. In the control group four had been abroad for brief periods: one to the USA, one to Malta and France, one to Malaya and Eritrea, and one to Gibraltar. One had suffered from hepatitis and one had had poliomyelitis. The numbers included in the questionnaire were too small to draw sound conclusions.

This work supports the findings of Drs Vandervelde and Mortimer, who showed that exposure to hepatitis B in Britain is infrequent. It is, indeed, a small fraction of that observed in the United States.'

A M A ABbas M D DENTON R A FranCIS

Department of Microbiology Rotherham District General Hospital, Rotherham S60 2UD

1 Dienstag JL, Ryan DM. Occupation exposure to immunization? Am $\mathcal{f}$ Epidemiol 1982;115:26-39.

\section{Chronic hepatitis in the 1980 s}

SIR,-We were interested in the excellent leading article by $\mathrm{Dr}$ John Hegarty and $\mathrm{Dr}$ Roger Williams (23 March, p 877) and would like to refer to a few of the issues they raised. We fully support their view that it can at times be extremely difficult to distinguish between chronic persistent and chronic active hepatitis. It is our policy to repeat the liver biopsy in such patients after an interval of six months even in the absence of clinical or biochemical change.

We believe it is still premature to attribute histological change to viruses known or assumed to be present. Thus in parenteral drug abusers with known hepatitis $B$ virus infection our findings suggest that non $\mathrm{A}$, non $B$ viruses represent the initial viral insult to the liver in over two thirds of the patients and probably contribute to the histological findings in no less than $90^{\prime \prime}$ " of patients.' In addi- tion we believe that hepatitis D virus ( $\delta$ agent) may have a major contributory role in chronic active hepatitis associated with hepatitis B virus."

Finally, it is our experience that chronic active hepatitis associated with hepatitis B has a better prognosis than chronic active hepatitis not associated with the $B$ virus. ${ }^{3}$

JOHN FIELDING

Department of Medicine and Gastroenterology,

Gerald Doyle

Department of Pathology,

The Charitable Infirmary,

1 Fielding JF, Shattock AG, Doyle GD, Kelly MG Non A non $B$ hepatitis in parenteral drug abusers. Irish Med F 1983;76:414-5

2 Shattock AG, Arthurs Y, Doyle GD, Fielding JF. Chronic active hepatitis in intravenous drug abusers Sci $1984 ; 153: 17-9$.

3 Arthurs Y, Doyle GD, Fielding JF. The course of chronic active hepatitis. Irish $\mathcal{f}$ Med Sci 1982;151:

\section{Informed consent from the mentally ill}

SIR,-I produced the Horizon film on Friern Hospital. Until recently psychiatric hospitals have been reluctant to let television crews on the premises to film patients, for the kind of reasons discussed by $\mathrm{Dr} \mathrm{R}$ L Palmer (23 March, p 931). If some hospitals have now changed their minds it is perhaps because the public image of hospital psychiatry has become so unfavourable that the closure of hospitals is planned by the government.

Friern Hospital provided me with a consent protocol. We filmed only those patients who had provided a written consent, asked for once. The written consents of their consultants and their next of kin (when they could be contacted) were also required. The chairman of the hospital ethical committee and the administrator of the hospital viewed the film before transmission, with powers to protect the rights of patients from abuse.

Nevertheless, Dr Palmer has a very good point. Were the patients shown in the film really the best judges of their own interests, despite the views of their consultants and relations? It is a very difficult question to answer. I have only to look at television to realise what extraordinary revelations mentally well people and "reasonable men" are prepared to make about themselves. That this happens would seem to indicate that well people have ideas of their own self interest which may at times be surprising and that the examples cited by $\mathrm{Dr}$ Palmer are not that unusual. I am pleased to report that all the patients who appeared in my film and who I spoke to afterwards said that they had enjoyed the experience.

Fisher DILKF

BBC Kensington House,
London $\mathbb{W}^{\prime} 12$

\section{Metoclopramide versus chlorpromazine} in controlling nausea and vomiting induced by cytotoxic drugs

SIR,-We would like to comment on the conclusions drawn by Dr David Cunningham and others from their study comparing the antiemetic efficacy of high dose metoclopramidc versus intramuscular chlorpromazine for cytotoxic induced vomiting (23 February, $n$ 604). They infer from their data that whereas high dose metoclopramide is better in 
controlling platinum associated vomiting it is no better than chlorpromazine for chemotherapeutic regimens not including cisplatin. We question whether it is reasonable on the evidence to conclude that high dose metoclopramide is not more effective in the second category of patients. Our own experience (unpublished) has been that the antiemetic activity of high dose metoclopramide is dose and schedule dependent in patients on cisplatin chemotherapy and that a minimum serum concentration of $850 \mathrm{ng} \mathrm{ml}$ has to be maintained during at least the first six hours after the cisplatin infusion. In the series of $\mathrm{Dr}$ Cunningham and his colleagues a small loading dose of $50 \mathrm{~g}$ was used with a continuous infusion of about $0.4 \mathrm{mg} / \mathrm{kg}$ /hour thereafter, which would not be expected to achieve the desired plasma concentration. More importantly, in their study the participation of several centres implies that the assessment of subjective end points, especially nausea and "patient preference," would have been rather variable. How many observers were there in all, and was a single standard questionnaire used by these observers?

We strongly endorse the efforts of the authors in attempting to improve the quality of patients' experiences in facing the rigours of cytotoxic chemotherapy and would encourage other research in this area. For patients on cisplatin chemotherapy major advances have already been made in the control of these side effects. It would be a pity, however, if potentially effective remedies were to be discarded for the wrong reasons.

S G ALLAN

E J BAYLISS

P S WARRINGTON

R C F LEONARD

Department of Clinical Oncology,

Western General Hospital,

${ }_{*}^{*}$ Dr Cunningham and Dr Soukop reply below.-ED, $B M \mathcal{H}$.

SIR,-The issue of plasma metoclopramide concentrations and antiemetic control is important and deserves comment. Meyer et al were the first to focus attention on the need to obtain a plasma metoclopramide concentration of at least $850 \mathrm{ng} \mathrm{ml} \mathrm{six} \mathrm{hours} \mathrm{after} \mathrm{cisplatin}$ administration to optimise control of emesis. ${ }^{1}$ It is probable that our loading dose and continuous intravenous infusion (total dose 5.5 $\mathrm{mg} \mathrm{kg}$ ) did not allow such a plasma concentration to be reached at six hours and that a loading dose of $2-3 \mathrm{mg} \mathrm{kg}$ would be required to achieve this. However, other workers using a similar dose of metoclopramide ( $6 \mathrm{mg}$ $\mathrm{kg}$ ) have shown adequate control of emesis with an acceptable level of side effects. ${ }^{3}$ Moreover, for cytotoxic regimens without cisplatin the current evidence would suggest that there is no clear relation between plasma concentration and control of emesis ${ }^{4}$; indeed, a recent clinical study showed no apparent advantage of increasing the dose of metoclopramide beyond $20 \mathrm{mg}$ (stat) intravenously every two hours for six doses."

A likely explanation for these findings is that there is a lower plasma threshold for optimum control of emesis induced by cytotoxic drugs other than cisplatin because with these drugs metoclopramide exerts its antiemetic effect by a central, rather than peripheral, pathway. In practical terms this means that escalating the dose of metoclopramide to improve emesis control for cytotoxic regimens without cisplatin is unlikely to be fruitful. Furthermore, although it may be acceptable to give an antiemetic as an intravenous infusion in circumstances where a prolonged intravenous infusion is necessary for the safe delivery of the cytotoxic agent (such as cisplatin) it hardly seems sensible that such a method should be used where a regimen is given by an intravenous bolus or short intravenous infusion. In this context, we have recently shown using the combination of an oral synthetic cannabinoid (nabilone) and prochlorperazine that emesis control is possible in over $80^{\prime \prime}$ " of patients receiving cytotoxic regimens without cisplatin, ${ }^{6}$ which enables the chemotherapy to be administered on an outpatient basis.

Regarding the methods, ours was a prospective multicentre study so the same questionnaire was used by all participating centres, and there was a total of five observers, which is not unreasonable given the size of the study. The comment with respect to subjective assessment is not relevant since each patient acted as his own control. Therefore we feel that our conclusions were valid and that high dose metoclopramide is not an appropriate first line antiemetic for cytotoxic regimens without cisplatin.

\section{CUNNINGHAM}

M SOUKOP

Department of Medical Oncology;

Glasgow Royal Infirmary
Glasgow G4 OSF

1 Meyer BR, Lewin M, Draver DE, Pasmentier M, Lonski L, Reidenberg MM. Optimizing metoclopramide control of cis-platin induced emesis.
Ann Intern Med 1984;100:393.

2 Homesley HD, Gainey JM, Jobson VW, et al. Metoclopramide. N Engl 7 Med 1982;307:250.

3 Strum SB, McDermed JE, Opfell RW, et al. Intravenous metoclopramide and effective antiemetic Taylor WB, Bateman DN. High dose metoclopramide - preliminarv pharmacokinetic studies. $B r \mathcal{J} C l i n$ Pharmacol 1983;16:341-2.

5 Strum SB, McDermed JE, Pileggi J, Reich LP, Whitaker $\mathrm{H}$. Intravenous metoclopramide: prevention of chemotherapy-induced nausea and vomiting. Cancer 1984;53:1432-9.

6 Cunningham D, Forrest GJ, Gilchrist NL, Calder I Soukop M. A comparative study of nabilone and prochlorperazine versus nabilune and placebo in the Cancer in press.

\section{Unithiol in Wilson's disease}

SIR, - We found it difficult to understand why Dr J M Walshe had decided to try the chelating agent unithiol, an agent with unproved merit, for the treatment of Wilson's disease in a boy who had developed intolerance towards two other chelating agents (penicillamine and triethylene tetramine) (2 March, p 673).

Until recently patients with Wilson's disease had no choice. Chelating therapy was the only treatment available, and when untreated the disease is invariably fatal. Penicillamine became regarded as the best of the chelating compounds. It may be given orally and was found to be less toxic than dimercaprol. However, treatment with penicillamine was not completely satisfactory: in some patients neurological signs increased during the tirst weeks of treatment and a few patients developed severe intolerance to penicillamine. ${ }^{1}$ Because of its potential toxicity penicillamine had to be given in minimal doses during long term therapy, with the risk of a reaccumulation of copper.

There is sufficient evidence to show that Wilson's disease can also be treated effectively with oral zinc and that patients who do not tolerate chelating therapy may profit greatly from the change to zinc. ${ }^{2} \mathrm{Zinc}$ is easily tolerated by most patients.

It should be emphasised that chelating therapy and oral zinc therapy differ completely in their way of action: the former induces the excretion of copper via the urine, the latter via the stools. Zinc can be given as zinc sulphate or in the form of other salts of low toxicity. A dose of $600-900 \mathrm{mg}$ zinc sulphate a day is usually sufficient to obtain a good result.

In view of the side effects in two of his three patients we were astonished to read that Dr Walshe concludes that unithiol might become a fall back treatment for patients who do not tolerate penicillamine. When chelating agents were the only possibility for patients with Wilson's disease, many patients profited from Dr Walshe's discovery that penicillamine could be taken by mouth and induce cupriuresis. $^{3}$ Now oral zinc therapy is available-an effective treatment of low toxicity. After such severe complications caused by two chelating agents it would have been a more rational therapeutic decision to have started zinc therapy.

TJAARD U HOOGENRAAD JAN VAN HATTUM

State University Hospital,

3500 CG Utrecht

1 Scheinberg IH, Sternlieb I. Wilson's disease. Major problems in internal medicine. Vol 23. Philadelphia: W B Saunders, 1984

2 Hoogenraad TU, Van den Hamer CJA, Van Hattum J. Effective treatment of W'ilson's disease with ora zinc sulphate: two case reports. Br Med f $1984 ; \mathbf{2 8 9}$

walshe Lancet 1956;i:125-6.

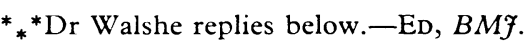

SIR,-I am impressed by the enthusiasm of Drs Hoogenraad and Van Hattum for the use of zinc sulphate in the treatment of Wilson's disease. If they cannot understand why I did not use this drug in the patient referred to in my short report of 2 March I can only refer them to my letter, also in the British Medical Fournal, of 1 September $1984 .^{1}$ From the difference in our two experiences of zinc sulphate I can only conclude that the gastric mucosas of his patients are more resistant to irritants than those of my patients. As to his assertion that unithiol is untried in the treatment of Wilson's disease I must again refer him to published reports; the drug has been in use at least since the late 1950s."

J W WLSHE

Department of Medicine,

Addenbrooke's Hospit

1 W'alshe JM. Treatment of Wilson's disease with zinc sulphate. BrMed $\mathcal{f} 1984 ; \mathbf{2 8 9}: 558-9$.

2 Konovalov NV, Muttel'Shtedt AA, Bauman LK, Gotovtseva EV. Copper metabolism in hepatolenticular degeneration thiol therapy. Zh Nevropat
Psikhiatr 1957;57:39-48.

\section{Cleft lip and palate}

SIR,-It was of great interest to read the recent article in your series "Plastic and Reconstructive Surgery"' (23 February, p 625). However, we were disappointed to find no mention of the importance of preventive dental care for children with cleft lips and palates. Poor dental health can make successful orthodontic treatment extremely difficult and will jeopardise the final result achieved in these 